\title{
Determination of the Sequence Distribution of Chlorines in Chlorinated Polyethylenes with the Aid of Monte Carlo Simulation
}

\author{
Takanori Saito and Yukihiro Matsumura \\ Central Research Laboratory, Showa Denko Co., \\ 2-24-60 Tamagawa, Ohta-ku, Tokyo, Japan.
}

(Received February 10, 1972)

\begin{abstract}
Monte Carlo simulation was carried out to specify the most probable model sequence and to reveal the sequence distribution of chlorines in chlorinated polyethylene(CPE). The simulation was also applied to study those of hydrogenated poly(vinyl chloride)(HPVC) and vinyl chloride-ethylene copolymer(VC-Et) for a comparison with those of CPE. The simulation was executed with the conditional probabilities of the second order defined in terms of the actual existence probabilities of triads which can be obtained by NMR spectroscopy. Monitor quantities relating to long methylene sequence and degree of chlorination were introduced into the simulation as a criterion of a convergence. When the convergence conditions were satisfied after a few trials, a linear model sequence composed of one thousand carbons was considered to be the most probable.

From the inspection of the model sequence thus determined, it can be pointed out that the distribution of chlorine atoms along the CPE chain is substantially random, being different from those of HPVC and VC-Et. The sequence distribution of various chemical units in the molecular chain was also determined readily and quantitatively without any contradiction by reckoning each sequential unit along the model sequence.

KEY WORDS Chlorinated Polyethylene / Vinyl Chloride-Ethylene Copolymer / Hydrogenated Poly(vinyl chloride) / NMR Spectroscopy / Monte Carlo Method / Computer Simulation / Conditional Probability of the Second Order / Most Probable Model Sequence / Sequence Distribution of Chlorines /
\end{abstract}

It is well known that even if the monoad compositions are quite identical in copolymers, the physical properties are apt to depend strongly on the sequence distribution of different units along the molecular chain. The difference of some viscoelastic properties of block, random and alternate copolymers ${ }^{1-4}$ is just an example. Such being the case, it should be necessary to specify the sequence distributions of various units in the characterization of the microstructure of copolymers.

High-resolution nuclear magnetic resonance (NMR) spectroscopy is readily available for studying the microstructure of copolymers and was applied to the study of chlorinated polyethlyne(CPE). ${ }^{5}$ However, direct information from NMR is usualy nothing more than triad informations or the like. Thus, we must resort to some statistical calculations in order to obtain polyad information.

The sequence distributions of different units in copolymers are often evaluated from the reactivity ratios of monomers with the consideration of the effect arising from the penultimate unit. $^{6}$ On the other hand, with substituted polymers such as CPE and chlorosulfonated polyethylene(CSPE), a statistical calculation was skillfully carried out by Frensdorff, et al., ${ }^{7}$ using the conditional probabilities estimated from the reaction selectivity of chlorinated $n$-paraffins. These calculations were especially applied to the sequence distribution of chlorines in CPE. A similar investigation was also developed for CSPE by Brame. ${ }^{8}$

In the statistical calculation stated above, however, there are often rather inevitable deviations 
from experimental results because of an inadequate estimation of conditional probabilities. For instance, though the formulation of Frensdorff, et al., is excellent and highly suitable for extending the triad information to the polyad information, their results for the monoad such as $-\left(\mathrm{CCl}_{2}\right)$ and - $(\mathrm{CHCl})$ - in $\mathrm{CPE}$ molecules are not entirely in agreement with those obtained by our NMR study. $^{5}$ From this fact, their estimation of the conditional probabilities may be inadequate for those of the chlorination of polyethylene. In this sense, if the triad information actually obtained from the NMR study were regarded as conditional probabilities of the second order instead of the estimation from model reactions of $n$ paraffins, the sequence distribution would be more exactly determined by the statistical calculation or by the Monte Carlo simulation by means of a computer. The latter simulation is used in the present investigation on the basis of quantitative triad informations from the NMR study described in our previous paper, ${ }^{5}$ wherein the same samplecode as those in that paper are used in this article.

As was shown in the previous study, ${ }^{5}$ it is very difficult by the NMR-spectroscopy to reveal the distribution of a longer methylene sequence than three in the CPE molecule. For this reason, a variable parameter $(Y)$ which defines the mole fraction of asterisked methylene in the unit $-\mathrm{CHCl}-\mathrm{CH}_{2}-\left(\mathrm{CH}_{2}\right)_{n}-\mathrm{CH}_{2}-\mathrm{CHCl}-$ is specificially introduced into the simulation. After a few trials of the simulation with the variation of $Y$, when the convergence conditions are satisfied, a simulated sequence of CPE will be considered as the most probable sequence as determined self-consistently, and useful information on the sequence distribution of various units will be readily obtained without any contradiction. This intention will succeed when the assignment and other treatments of calculation are throughly correct, and conversely the calculation will be verified when the above intentions turn out a success.

\section{SIMULATIONAL}

\section{Description of Variables and Parameters}

Variables such as $a_{1}, a_{2}, a_{3}, b, \ldots f$ and $g$ represent mole fraction of various chemical units as summarized in Table I. Mole fraction of
Table I. Mole fraction variables of chemical units ${ }^{a}$

\begin{tabular}{ccc}
\hline Chemical units & & Notation \\
\hline & $i \geqq 5$ & $a_{1}$ \\
& $i=4$ & $a_{2}$ \\
$-\mathrm{CHCl}-\left(\mathrm{CH}_{2}\right)_{i}-\mathrm{CHCl}-$ & $i=3$ & $a_{3}$ \\
& $i=2$ & $b$ \\
& $i=1$ & $c$ \\
$-\mathrm{CHCl}-\mathrm{CH}_{2}-\mathrm{CCl}_{2}-$ & & $d$ \\
$-\mathrm{CH}_{2}-\left(\mathrm{CHCl}_{j}-\mathrm{CH}_{2}-\right.$ & $j=1$ & $e$ \\
& $j \geqq 3$ & $f$ \\
\end{tabular}

a $c f$. Table $\mathrm{I}$ in the previons paper. ${ }^{5}$

polyads of longer than three methylene sequences are tentatively estimated from the following equations with parameters $\alpha$ and $\beta$ as described in our previous paper, ${ }^{5}$

$$
\begin{aligned}
& a_{1}=K(1+\alpha) S_{1}=A 5 \\
& a_{2}=K\left\{(1+\beta) S_{2}-\alpha S_{1}\right\}=A 4 \\
& a_{3}=K\left(S_{3}-\beta S_{2}\right)=A 3 \\
& K=\left(a_{1}+a_{2}+a_{3}\right) /\left(S_{1}+S_{2}+S_{3}\right)
\end{aligned}
$$

where $\alpha$ and $\beta$ are, so to speak, signal splitting parameters of overlapping signals appearing in the NMR spectrum arising from protons in long methylene sequences. $K$ and $S_{i}(i=1,2,3)$ are a normalizing factor and relative peak area of the chemical shift, respectively. Parameters $\alpha$ and $\beta$ are assumed to be 0.2 and 1.0, respectively, deduced from those of $\alpha, \omega$-dichloparaffins. ${ }^{5}$

Mole fractions of some triads listed in Table II are also estimated as

$$
\begin{aligned}
& a_{\mathrm{t}}=Y a_{1}+a_{2} / 2+a_{3} / 3 \\
& b_{\mathrm{t}}=(1-Y) a_{1}+b+a_{2} / 2+2 a_{3} / 3 \\
& f_{\mathrm{t}}=f+(1-Z) g \\
& g_{\mathrm{t}}=Z g
\end{aligned}
$$

where $Y$ and $Z$ are mean mole fractions of

Table II. Mole fraction variables of triads

\begin{tabular}{cc}
\hline Triad & Notation \\
\hline$-\mathrm{CH}_{2}-\mathrm{CH}_{2}^{*}-\mathrm{CH}_{2}-$ & $a_{\mathrm{t}}$ \\
$-\mathrm{CHCl}-\mathrm{CH}_{2}-\mathrm{CH}_{2}-$ & $b_{\mathrm{t}}$ \\
$-\mathrm{CHCl}-\mathrm{CH}^{*} \mathrm{Cl}-\mathrm{CH}_{2}-$ & $f_{\mathrm{t}}$ \\
$-\mathrm{CHCl}-\mathrm{CHCl}-\mathrm{CHCl}-$ & $g_{\mathrm{t}}$ \\
\hline
\end{tabular}


asterisked methylenes or methynes in following formulae, respectively.

$$
\begin{aligned}
& -\mathrm{CHCl}-\mathrm{CH}_{2}-\left(\mathrm{CH}_{2}\right)_{i-2}-\mathrm{CH}_{2}-\mathrm{CHCl}- \\
& -\mathrm{CH}_{2}-\mathrm{CHCl}-(\mathrm{CHCl})_{j-2}-\mathrm{CHCl}-\mathrm{CH}_{2}-
\end{aligned}
$$

If the mole fraction of $i$ methylene sequences and $j$ methyne sequences were $\phi_{i}$ and $\phi_{j}$, respectively, $Y$ and $Z$ are determined as follows:

$$
\begin{aligned}
& Y=\sum_{i=3}^{\infty}\left\{(i-2) \phi_{i}\right\} / \sum_{i=3}^{\infty} i \phi_{i} \\
& Z=\sum_{j=3}^{\infty}\left\{(j-2) \phi_{j}\right\} / \sum_{j=3}^{\infty} j \psi_{j}
\end{aligned}
$$

As in a previous paper, ${ }^{5} Z$ is assumed to be 0.8 . On the other hand, $Y$ is treated as a variable in the present simulation, because the variety of the methylene sequence length seemed to be more characteristic than the methyne sequence length in the CPE chain.

\section{Definition of Conditional Probability}

Carbon atoms in the skeletal chain of a CPE molecule are enumerated consecutively from the terminal one starting with the first, and the $N$-th carbon is designated as $I S(N)$. Chemical units such as $\mathrm{CH}_{2}, \mathrm{CHCl}$, and $\mathrm{CCl}_{2}$ are represented by the integer 0,1 , and 2 , respectively, according to the number of chlorine atoms substituted for a methylene. An existent probability of an arbitrary triad is written as $T(I J K)$ when the following conditions are satisfied

$$
I S(N-2)=I, \quad I S(N-1)=J, \quad \text { and } \quad I S(N)=K
$$

where $I, J$, and $K$ are one of the integers 0,1 , and 2. The triad probability $T(I J K)$ is readily
Table III. Existent probabilities of triads

\begin{tabular}{ll}
\hline$T(I J K)$ & Variables \\
\hline$T(000)$ & $a_{\mathrm{t}}$ \\
$T(100)$ & $0.5 b_{\mathrm{t}}$ \\
$T(001)$ & $0.5 b_{\mathrm{t}}$ \\
$T(101)$ & $c$ \\
$T(102)$ & $0.5 d$ \\
$T(201)$ & $0.5 d$ \\
$T(010)$ & $e$ \\
$T(011)$ & $\left(0.5 f_{\mathrm{t}}+0.1 g_{\mathrm{t}}\right)$ \\
$T(110)$ & $\left(0.5 f_{\mathrm{t}}+0.1 g_{\mathrm{t}}\right)$ \\
$T(111)$ & $0.8 g_{\mathrm{t}}$ \\
\hline
\end{tabular}

determined from the mole fractions such as $a_{1}$, $a_{2}, a_{3}, b, \ldots g$. For computing $T(I J K)$, the symmetry,

$$
T(I J K)=T(K J I)
$$

is taken into consideration. The $T(I J K)$ 's are calculated with the variables listed in Tables I and II, as shown in Table III.

Next, a conditional probability $\boldsymbol{P}\{\boldsymbol{K} \mid \boldsymbol{I J}\}$ is defined in terms of the $T(I J K)$ as follows

$$
P\{K \mid I J\}=T(I J K) / \sum_{K=0}^{2} T(I J K)
$$

The conditional probability thus defined is considered to be the transition probability of the second order. Details of the conditional probabilities are summarized in Table IV, where the

\begin{tabular}{|c|c|c|c|c|}
\hline \multicolumn{2}{|c|}{ Conditions } & \multicolumn{3}{|c|}{ Conditional probabilities } \\
\hline$\underset{I}{I S(N-2)}$ & $\underset{J}{I S(N-1)}$ & $K=0$ & 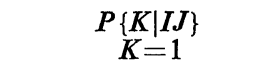 & $K=2$ \\
\hline 0 & 0 & $T(000) / T 00$ & $T(001) / T 00$ & 0.00 \\
\hline 0 & 1 & $T(010) / T 01$ & $T(011) / T 01$ & 0.00 \\
\hline 0 & 2 & 1.00 & 0.00 & 0.00 \\
\hline 1 & 0 & $T(100) / T 10$ & $T(101) / T 10$ & $T(102) / T 10$ \\
\hline 1 & 1 & $T(110) / T 11$ & $T(111) / T 11$ & 0.00 \\
\hline 2 & 0 & 0.00 & 1.00 & 0.00 \\
\hline- & 1 & $\{T(010)+T(110)\} / T 1$ & $\{T(011)+T(111)\} / T 1$ & 0.00 \\
\hline
\end{tabular}
fact that the chemical unit $\mathrm{CCl}_{2}$ exists in one and only sequence ${ }^{5}$ such as

$$
-\left(\mathrm{CHCl}-\mathrm{CH}_{2}-\mathrm{CCl}_{2}-\mathrm{CH}_{2}\right)_{i}-\mathrm{CHCl}-(i \geqq 1)
$$

is under consideration, and the normalizing factors $\sum_{K=0}^{2} T(I J K)$ are shown in Table V. The

Table IV. Conditional probabilities 
Table V. Normalizing factors

\begin{tabular}{ll}
\hline$T I J$ & $\sum T(I J K)$ \\
\hline$T 00$ & $T(000)+T(001)$ \\
$T 01$ & $T(010)+T(011)$ \\
$T 10$ & $T(100)+T(101)+T(102)$ \\
$T 11$ & $T(110)+T(11)$ \\
$T 1$ & $T 01+T 11$
\end{tabular}

probability $P\{K \mid 1\}$ listed in the last column of Table IV is used for the determination of $I S(2)$, and $I S(1)$ is assumed a apriori to be a methyne unit. However, the validity of the simulation is conserved in the case of such a large carbon number as one thousand as in the present simulation. The conditional probabilities concerned with the probabilities $T(000), T(100)$ and $T(001)$ depend on the parameter $Y$, because $T(000)$, $T(100)$ and $T(001)$ are function of $a_{\mathrm{t}}$ and $b_{\mathrm{t}}$, each depending on the parameter $Y$ as shown in eq 5 and 6 .

Determination of $I S(N)$

The degree of chlorination of the $N$-th carbon, $I S(N)$ is determined from comparison of the $N$-th pseudorandom number, $R D N(N)$ generated by the subroutine equipped in a computer (IBM 360$4 \mathrm{H})^{9}$ with the conditional probability as follows,

$$
\begin{aligned}
& a \text { priori } \ldots \ldots \ldots \ldots \ldots \ldots I S(1)=1 \\
& R D N(2)_{n} \leqq(P\{0 \mid 1\}+n-1) / k \ldots I S(2)=0 \\
& R D N(2)_{n}>(P\{0 \mid 1\}+n-1) / k \ldots I S(2)=1
\end{aligned}
$$

where the terminal unit of CPE chain is assumed to be methyne and $I S(2)$ is not equal to 2 , because the $-\mathrm{CHCl}-\mathrm{CCl}_{2}-$ is absent in the $\mathrm{CPE}$ chain as reported in a previous paper. ${ }^{5}$

As for the succeeding $N(N \geqq 3)$, the following operations are repeated.

$$
\begin{gathered}
R D N(N)_{n} \leqq(P\{0 \mid I J\}+n-1) / k \ldots I S(N)=0 \\
(P\{0 \mid I J\}+n-1) / k<R D N(N)_{n} \\
\leqq(P\{0 \mid I J\}+P\{1 \mid I J\}+n-1) / k \\
\ldots . I S(N)=1 \quad(18) \\
R D N(N)_{n}>(P\{0 \mid I J\}+P\{1 \mid I J\}+n-1) / k \\
\ldots I S(N)=2
\end{gathered}
$$

In these equations, $n$ and $k$ are integers for improvement on inferior independence between successive numbers in the series of pseudorandom numbers generated by a computer. Details on an application of the pseudorandom number are described in the appendix of this paper.

\section{Flow Chart of Computer Simulation}

The computer simulation is carried out according to the flow chart as briefly shown in Figure 1. For a given arbitrary value of the parameter $Y$ and the triad probability determined by NMR spectroscopy, the first trial (a count number $M$ is equal to unity) is executed and further trials are repeated after $Y_{M+1}, A 5_{M+1}, A 4_{M+1}$, and $A 3_{M+1}$

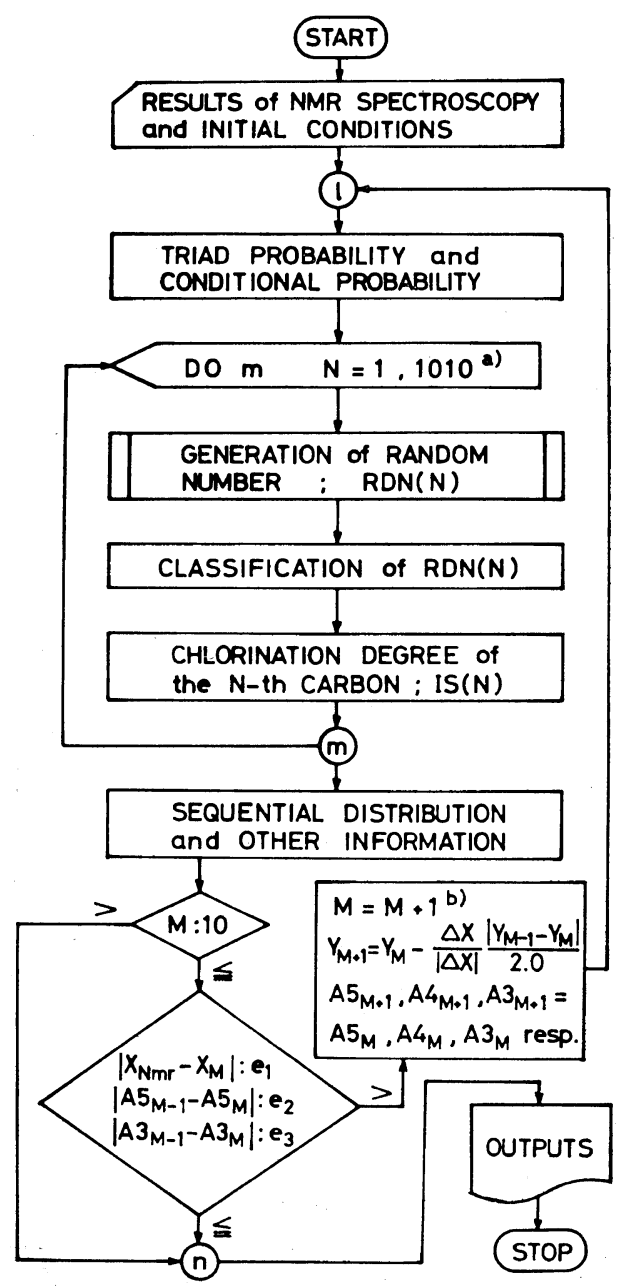

Figure 1. The outline of the flow in the computer simulation. a) The statement in FORTRAN language which means recurrent calculation till $N$ reaches to one thousand and ten starting with unity. b) The statement in FORTRAN language which means substituting $(M+1)$ for $M$. 


\section{T. Saito and Y. Matsumura}

\begin{tabular}{|c|c|c|}
\hline $\begin{array}{l}\text { SAMPLE } \\
\text { AIFE }\end{array}$ & $\begin{array}{l}\text { IS(N) } \\
0010100001000000000100000010100000000001000000000000100000000000000000000000000000000000000000000001\end{array}$ & $\begin{array}{l}x_{5}(w t \%) \\
16.3\end{array}$ \\
\hline$A 4 W$ & 00010100001010000000101010010100000000001000000000000100000000000000000000000000000000000100000000001 & 21.9 \\
\hline A5FC & 00000000101010100000000101000000000010100000100010000010000000000000000010000001000100010010000000100 & 31.0 \\
\hline $54 \mathrm{~W}$ & 0100100000100010101000010100010001010001001010100010100000000100101000100100001000101000000101010100 & 40.6 \\
\hline A10W & 1010201000100010101000010101010001010001001010100010100000000100101000100101001010102010000101010100 & 43.2 \\
\hline A11FE & 0000000102010010010101010101010100001011000010001000001001001010100010010101001101001020100000001001 & 49.5 \\
\hline A13FE & 1010100102011011010101020101010101001011010010101001010101001010100101010101001101101020110101010201 & 57.8 \\
\hline A15FE & 1010110201102011020162010201020101011111010110102010102011102010101020111111102010201020110101011102 & 66.6 \\
\hline HPVC & 1010010101001001000001010101010101000101000000010101010000000010001010001010100010001001010100100101 & 44.9 \\
\hline VC-Et & $1010100010101010101010100 c 000 c 00000 c 1010101010101000001000001010100000010101010101000010100000001000$ & 47.8 \\
\hline
\end{tabular}

Figure 2. Partial sequence in the most probable model sequence of CPE's, HPVC and VC-Et by the Monte Carlo simulation; where $X_{\mathrm{s}}$ is the mean chlorine content of a molecular chain determined by the simulation.

Table VI. Comparison of simulated results with input data

\begin{tabular}{|c|c|c|c|c|c|c|c|c|c|c|}
\hline & AIFE & $\mathrm{c}=0.166^{\mathrm{b}}$ & $\mathrm{A} 4 \mathrm{~W}$ & $X_{\mathrm{c}}=0.244$ & A5FC & $X_{\mathrm{c}}=0.311$ & S4W & $X_{\mathrm{c}}=0.416$ & A10W & $X_{\mathrm{c}}=0.432$ \\
\hline imeter & Ante $S$ & Post $S$ & Ante $S$ & Post $S$ & Ante $S$ & Post $S$ & Ante $S$ & Post $S$ & Ante $S$ & Post $S$ \\
\hline$X^{\mathrm{a}}$ & 0.176 & 0.163 & 0.246 & 0.219 & 0.310 & 0.310 & 0.399 & 0.406 & 0.379 & 0.432 \\
\hline$E_{1}$ & 0.916 & 0.924 & 0.872 & 0.890 & 0.825 & 0.825 & 0.744 & 0.736 & 0.772 & 0.721 \\
\hline$V_{1}$ & 0.084 & 0.076 & 0.128 & 0.110 & 0.175 & 0.175 & 0.257 & 0.264 & 0.218 & 0.265 \\
\hline$D_{1}$ & 0.000 & 0.000 & 0.000 & 0.000 & 0.000 & 0.000 & 0.000 & 0.000 & 0.009 & 0.014 \\
\hline$T 000$ & 0.759 & 0.790 & 0.617 & 0.718 & 0.458 & 0.517 & 0.302 & 0.306 & 0.299 & 0.295 \\
\hline$T 100$ & 0.131 & 0.118 & 0.198 & 0.126 & 0.313 & 0.265 & 0.338 & 0.332 & 0.333 & 0.295 \\
\hline$T 101$ & 0.026 & 0.017 & 0.057 & 0.047 & 0.054 & 0.043 & 0.103 & 0.098 & 0.122 & 0.104 \\
\hline$T 102$ & 0.000 & 0.000 & 0.000 & 0.000 & 0.000 & 0.000 & 0.000 & 0.000 & 0.019 & 0.028 \\
\hline$T 010$ & 0.084 & 0.075 & 0.128 & 0.109 & 0.175 & 0.175 & 0.257 & 0.264 & 0.218 & 0.265 \\
\hline$T 110$ & 0.000 & 0.000 & 0.000 & 0.000 & 0.000 & 0.000 & 0.000 & 0.000 & 0.000 & 0.000 \\
\hline$T 111$ & 0.000 & 0.000 & 0.000 & 0.000 & 0.000 & 0.000 & 0.000 & 0.000 & 0.000 & 0.000 \\
\hline$T 020$ & 0.000 & 0.000 & 0.000 & 0.000 & 0.000 & 0.000 & 0.000 & 0.000 & 0.014 & 0.014 \\
\hline
\end{tabular}

$\begin{array}{llllll}Y_{M} & 0.891 & 0.878 & 0.879 & 0.879 & 0.797\end{array}$

\begin{tabular}{|c|c|c|c|c|c|c|c|c|c|c|}
\hline \multirow{2}{*}{$\begin{array}{l}\text { Sample } \\
\text { Pa- } \\
\text { rameter } \\
\end{array}$} & \multicolumn{2}{|c|}{$\mathrm{A} 11 \mathrm{FE} X_{\mathrm{c}}=0.507$} & \multicolumn{2}{|c|}{ A13FE $X_{c}=0.595$} & \multicolumn{2}{|l|}{ A15FE $X$} & \multicolumn{2}{|l|}{ HPVC-1 } & \multicolumn{2}{|c|}{ Vc-Et $X_{\mathrm{c}}=0.504$} \\
\hline & Ante $S$ & Post $S$ & Ante $S$ & Post $S$ & Ante $S$ & Post $S$ & Ante $S$ & Post $S$ & Ante $S$ & Post $S$ \\
\hline$X$ & 0.484 & 0.495 & 0.578 & 0.578 & 0.674 & 0.666 & 0.420 & 0.449 & 0.503 & 0.478 \\
\hline$E_{1}$ & 0.661 & 0.648 & 0.523 & 0.527 & 0.313 & 0.347 & 0.720 & 0.686 & 0.612 & 0.648 \\
\hline$V_{1}$ & 0.317 & 0.329 & 0.435 & 0.427 & 0.602 & 0.562 & 0.280 & 0.313 & 0.389 & 0.352 \\
\hline$D_{1}$ & 0.022 & 0.024 & 0.043 & 0.047 & 0.084 & 0.091 & 0.000 & 0.000 & 0.000 & 0.000 \\
\hline$T 000$ & 0.191 & 0.160 & 0.048 & 0.031 & 0.007 & 0.002 & .248 & 0.251 & 0.188 & 0.227 \\
\hline$T 100$ & 0.274 & 0.296 & 0.157 & 0.169 & 0.019 & 0.016 & 0.254 & 0.243 & 0.142 & 0.137 \\
\hline$T 101$ & 0.152 & 0.146 & 0.231 & 0.235 & 0.120 & 0.147 & 0.219 & 0.192 & 0.282 & 0.284 \\
\hline$T 102$ & 0.044 & 0.048 & 0.086 & 0.093 & 0.168 & 0.183 & 0.000 & 0.000 & 0.000 & 0.000 \\
\hline$T 010$ & 0.302 & 0.306 & 0.332 & 0.333 & 0.149 & $0.1: 34$ & 0.280 & 0.313 & 0.389 & 0.352 \\
\hline$T 110$ & 0.015 & 0.022 & 0.078 & 0.063 & 0.226 & 0.224 & 0.000 & 0.000 & 0.000 & 0.000 \\
\hline$T 111$ & 0.000 & 0.000 & 0.025 & 0.029 & 0.227 & 0.203 & 0.000 & 0.000 & 0.000 & 0.000 \\
\hline$T 020$ & 0.022 & 0.024 & 0.043 & 0.047 & 0.084 & 0.091 & 0.000 & 0.000 & 0.000 & 0.000 \\
\hline$Y_{M}$ & \multicolumn{2}{|c|}{0.798} & \multicolumn{2}{|c|}{0.798} & \multicolumn{2}{|c|}{0.798} & \multicolumn{2}{|c|}{0.798} & \multicolumn{2}{|c|}{0.798} \\
\hline
\end{tabular}

a $X$ under the row of ante $S$ and post $S$ are mean chlorine content determined by the NMR-spectroscopy $\left(X_{\mathrm{N}}\right)$ and by the simulation $\left(X_{\mathrm{S}}\right)$, respectively.

b $X_{\mathrm{c}}$ is that by the chemical analysis. 
are substituted by $Y_{M}, A 5_{M}, A 4_{M}$ and $A 3_{M}$, respectively, till the conditions of convergence are satisfied.

As in a previous report, ${ }^{10}$ when the signal splitting parameters $\alpha$ and $\beta$ were treated as variables, the convergency was very poor. Accordingly in this paper, parameters $\alpha$ and $\beta$ are assumed to be constant (i.e., $\alpha=0.2, \beta=1.0$ ) which were reasonably estimated from those of $\alpha, \omega$ dichloroparaffins. On the other hand, $Y$ is con- sidered to be a variable parameter. As a result, good convergency is attained by a few trials in the calculating loop of the Monte Carlo simulation.

\section{RESULTS AND DISCUSSION}

\section{Model Sequence of CPE Chain}

The most probable model sequences of some CPE's having various mean degree of chlorination, and those of HPVC and VC-Et are partly

Table VII. Existent probability, $\operatorname{Pr}(N)$, of $-\left(\mathrm{CH}_{2}\right)_{N}-$ unit to total carbon number (\%)

\begin{tabular}{|c|c|c|c|c|c|c|c|c|c|c|c|c|c|c|c|}
\hline \multirow{2}{*}{ Sample } & \multicolumn{15}{|c|}{ Sequence number $(N)$} \\
\hline & 1 & 2 & 3 & 4 & 5 & 6 & 7 & 8 & 9 & 10 & 11 & 12 & 13 & 14 & $N \geqq 15 \quad N \geqq 5$ \\
\hline A1FE & 1.69 & 1.19 & 0.89 & 0.79 & 0.99 & 2.38 & 0.00 & 0.79 & 4.46 & 3.97 & 2.18 & 1.19 & 6.45 & 2.78 & \\
\hline A4W & 4.66 & 1.39 & 0.60 & 1.19 & 2.48 & 2.98 & 0.69 & 2.38 & 1.79 & 4.96 & 2.18 & 2.38 & 6.45 & 2.78 & .0981 .84 \\
\hline A5FC & 4.27 & 6.55 & 6.55 & 5.16 & 5.46 & 8.33 & 5.56 & 5.56 & 0.89 & 5.95 & 3.27 & 2.38 & 5.16 & 5.56 & 11.8559 .97 \\
\hline S4W & 9.82 & 12.30 & 11.31 & 6.75 & 8.43 & 6.55 & 4.86 & 7.94 & 1.79 & 0.99 & 1.09 & 0.00 & 0.00 & 0.00 & 1.7733 .42 \\
\hline $\mathrm{A} 10 \mathrm{E}$ & 14.02 & 10.12 & 10.12 & 6.75 & 6.94 & 6.55 & 4.86 & 6.35 & 1.79 & 1.98 & 0.00 & 0.00 & 1.29 & 0.00 & 1.3331 .09 \\
\hline A11FE & 19.34 & 13.49 & 11.61 & 7.14 & 6.45 & 3.57 & 1.39 & 0.79 & 0.89 & 0.00 & 0.00 & 0.00 & 0.00 & 0.00 & 0.0013 .09 \\
\hline A13FE & 32.84 & 12.50 & 3.87 & 2.78 & 0.00 & 0.60 & 0.00 & 0.00 & 0.00 & 0.00 & 0.00 & 0.00 & 0.00 & 0.00 & $0.00 \quad 0.60$ \\
\hline A15FE & 32.93 & 1.39 & 0.00 & 0.40 & 0.00 & 0.00 & 0.00 & 0.00 & 0.00 & 0.00 & 0.00 & 0.00 & 0.00 & 0.00 & 0.00 \\
\hline HPVC-1 & 19.24 & 7.74 & 7.74 & 7.14 & 6.45 & 5.36 & 3.47 & 6.35 & 0.89 & 0.00 & 2.18 & 0.00 & 0.00 & 0.00 & 2.0426 .74 \\
\hline $\mathrm{VC}-\mathrm{Et}$ & 28.37 & 3.57 & 3.87 & 3.18 & 3.47 & 4.17 & 2.08 & 0.79 & 0.00 & 2.98 & 3.27 & 1.19 & 3.87 & 0.00 & 3.9925 .81 \\
\hline
\end{tabular}

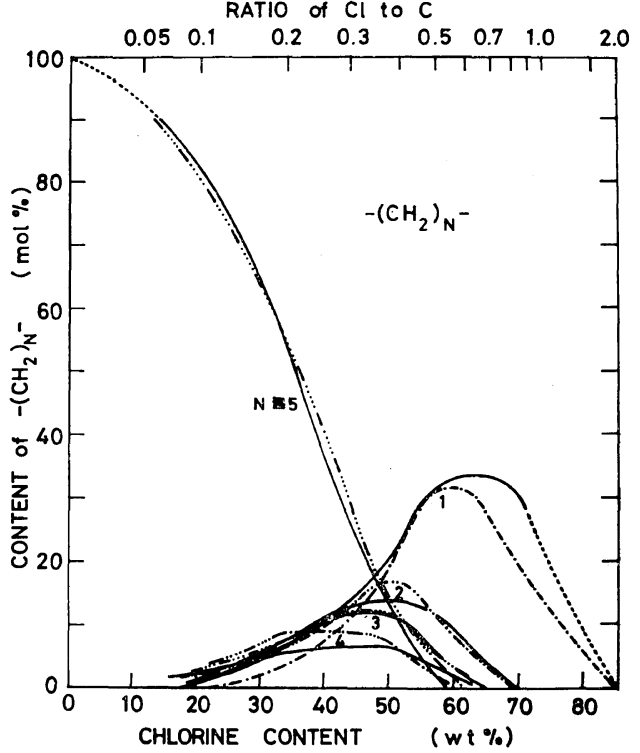

Figure 3. Content of methylene sequences, $-\left(\mathrm{CH}_{2}\right)_{N}-$, as a function of chlorine content $\left(X_{\mathrm{S}}\right)$; where the solid line and the dot-dash-line are those determined by the simulation and by eq 21 , respectively. shown in Figure 2, where the integer 0, 1, and 2 represent the chemical units of $\mathrm{CH}_{2}, \mathrm{CHCl}$, and $\mathrm{CCl}_{2}$, respectively.

The model sequences provide us with various informations such as mean chlorine content $\left(X_{\mathrm{s}}\right)$, mole fraction of the units $\mathrm{CH}_{2}\left(E_{1}\right), \mathrm{CHCl}\left(V_{1}\right)$, $\mathrm{CCl}_{2}\left(D_{1}\right)$ and mole fraction of various triads and polyads. These results are summarized in the row designated as post $S$ in Table VI and the input data obtained by NMR spectroscopy are also listed in the row of ante $S$ in the same table. The parameter $Y_{M}$ was also listed in Table VI. It can be pointed out that quantities such as $T(I J K), X_{\mathrm{s}}, E_{1}, V_{1}$, and $D_{1}$ between ante and post simulations are substantially in close agreement with each other. This fact verifies an availability of the simulation and also the adequancy of the assignments on triads described in a previous paper. 5

\section{Content of Long Methylene Sequences}

The frequency to locate $-\left(\mathrm{CH}_{2}\right)_{N}$ - in a CPE chain, $\operatorname{Fr}(N)$, can be readily obtained by the simulation. Hence the existence probability of 
Table VIII. Existent frequency, $\operatorname{Fr}(N)$, of $-\left(\mathrm{CHCl}-\mathrm{CH}_{2}\right)_{N}-$ unit to total carbon number (\%)

\begin{tabular}{|c|c|c|c|c|c|c|c|c|c|c|c|c|c|}
\hline \multirow{2}{*}{ Sample } & \multicolumn{13}{|c|}{ Sequence number $(N)$} \\
\hline & 1 & 2 & 3 & 4 & 5 & 6 & 7 & 8 & 9 & 10 & 11 & 12 & 13 \\
\hline A1FE & 4.5 & 1.2 & 0.1 & 0.1 & & & & & & & & & \\
\hline A4W & 3.7 & 1.2 & 1.0 & 0.1 & 0.3 & & & & & & & & \\
\hline A5FC & 9.9 & 2.6 & 0.4 & 0.3 & & & & & & & & & \\
\hline S4W & 10.6 & 3.6 & 1.3 & 0.5 & 0.2 & 0.3 & & & & & & & \\
\hline A10W & 8.1 & 3.5 & 1.6 & 0.2 & 0.5 & 0.1 & 0.1 & & & & & & \\
\hline $\mathrm{A} 11 \mathrm{FE}$ & 6.8 & 4.1 & 2.1 & 0.8 & 0.4 & 0.1 & - & 0.1 & & & & & \\
\hline $\mathrm{A} 13 \mathrm{FE}$ & 5.3 & 3.6 & 2.3 & 1.1 & 0.7 & 0.3 & - & 0.1 & 0.1 & - & 0.2 & & \\
\hline A15FE & 5.5 & 2.7 & 0.7 & 0.1 & & & & & & & & & \\
\hline HPVC-1 & 4.7 & 2.9 & 1.9 & 0.8 & 1.0 & 0.4 & 0.1 & 0.1 & 0.2 & - & - & 0.1 & \\
\hline $\mathrm{VC}-\mathrm{Et}^{\mathrm{a}}$ & 1.8 & 1.2 & 0.9 & 0.4 & 0.4 & 0.4 & 0.3 & 0.4 & 0.1 & 0.2 & - & 0.3 & 0.2 \\
\hline
\end{tabular}

a More long sequences $(N \geqq 13)$ exist i.e., $0.1(N=16), 0.1(N=20), 0.2(N=21)$.

Table IX. Existent frequency, $\operatorname{Fr}(N)$ of

$-\left(\mathrm{CHCl}-\mathrm{CH}_{2}-\mathrm{CCl}_{2}-\mathrm{CH}_{2}\right)_{N}-\mathrm{CHCl}-$ unit to total carbon number $(\%)$

\begin{tabular}{lcccc}
\hline \multirow{2}{*}{ Sample $^{a}$} & \multicolumn{5}{c}{ Sequence number $(N)$} \\
\cline { 2 - 5 } & 2 & 4 & 6 & 8 \\
\hline A10W & 1.0 & 0.2 & & \\
A11FE & 2.2 & 0.1 & & \\
A13FE & 4.4 & 0.2 & & \\
A15FE & 6.4 & 0.8 & 0.1 & 0.2 \\
\hline
\end{tabular}

a Other samples do not contain the unit $-(\mathrm{CHCl}-$ $\left.\mathrm{CH}_{2}-\mathrm{CCl}_{2}-\mathrm{CH}_{2}\right)_{N}-\mathrm{CHCl}-$.

that, $\operatorname{Pr}(N)$, is determined by following equation:

$$
\operatorname{Pr}(N)=\operatorname{NFr}(N)
$$

The results thus calculated by eq 20 are summerized in Table VII. While $\operatorname{Fr}(N)$ can be also determined by the theoretical treatment of Frensdorff, et al.,'s work ${ }^{7}$ as follows,

$$
\operatorname{Fr}(N)=E_{1}(1.0-A-B)^{2}(A+B)^{N-1}
$$

where $A, B$, and $E_{1}$ are the mole fraction of chemical units such as $-\left(\mathrm{CH}_{2}\right)_{N}-(N \geqq 3),-\left(\mathrm{CH}_{2}\right)_{2}-$ and $-\left(\mathrm{CH}_{2}\right)-$, respectively, which are directly obtained NMR spectroscopy. $\operatorname{Pr}(N),(N=1,2$, 3,4 , and $N \geqq 5$ ), determined by the simulation and by the latter theoretical calculation with eq 21 are substantially in close agreement each other as shown in Figure 3. The question about the extraordinarily high value of $\operatorname{Pr}(4)$ as shown in Figure 7 of the frevious paper $^{5}$ seemed to be resolved by the simulation. This fact is one of availabilities of the computer simulation.

Sequence Distribution of Various Units in a Molecular Chain

Sequence distributions of various units such as $-\left(\mathrm{CHCl}-\mathrm{CH}_{2}\right)_{N}-,-\left(\mathrm{CHCl}-\mathrm{CH}_{2}-\mathrm{CCl}_{2}-\right.$ $\left.\mathrm{CH}_{2}\right)_{N}-\mathrm{CHCl}-$ and $-(\mathrm{CHCl})_{N}-$ are expressed in terms of $\operatorname{Fr}(N)$ to locate them in a molecular

Table X. Existent frequency, $\operatorname{Fr}(N)$, of $-(\mathrm{CHCl})_{N}-$ unit to total carbon number $(\%)$

\begin{tabular}{lrccccccccccc}
\hline \multirow{1}{*}{ Sample } & \multicolumn{10}{c}{ Sequence number $(N)$} \\
\cline { 2 - 11 } & 1 & 2 & 3 & 4 & 5 & 6 & 7 & 8 & 9 & 10 & 11 & 12 \\
\hline A1FE & 7.5 & & & & & & & & & & & \\
A4W & 10.9 & & & & & & & & & & & \\
A5FC & 17.5 & & & & & & & & & & & \\
S4W & 26.4 & & & & & & & & & & & \\
A10W & 26.5 & & & & & & & & & & & \\
A11FE & 30.6 & 1.1 & & & & & & & & & & \\
A13FE & 33.3 & 1.7 & 1.0 & 0.1 & 0.3 & 0.2 & & & & \\
A15FE & 13.4 & 4.1 & 3.0 & 1.3 & 0.8 & 0.8 & 0.2 & 0.7 & 0.2 & 0.1 & 0.1 & 0.1 \\
HPVC-1 & 31.3 & & & & & & & & & & & \\
VC-Et & 35.2 & & & & & & & & & & & \\
\hline
\end{tabular}


Chlorine Distribution in Chlorinated Polyethylenes
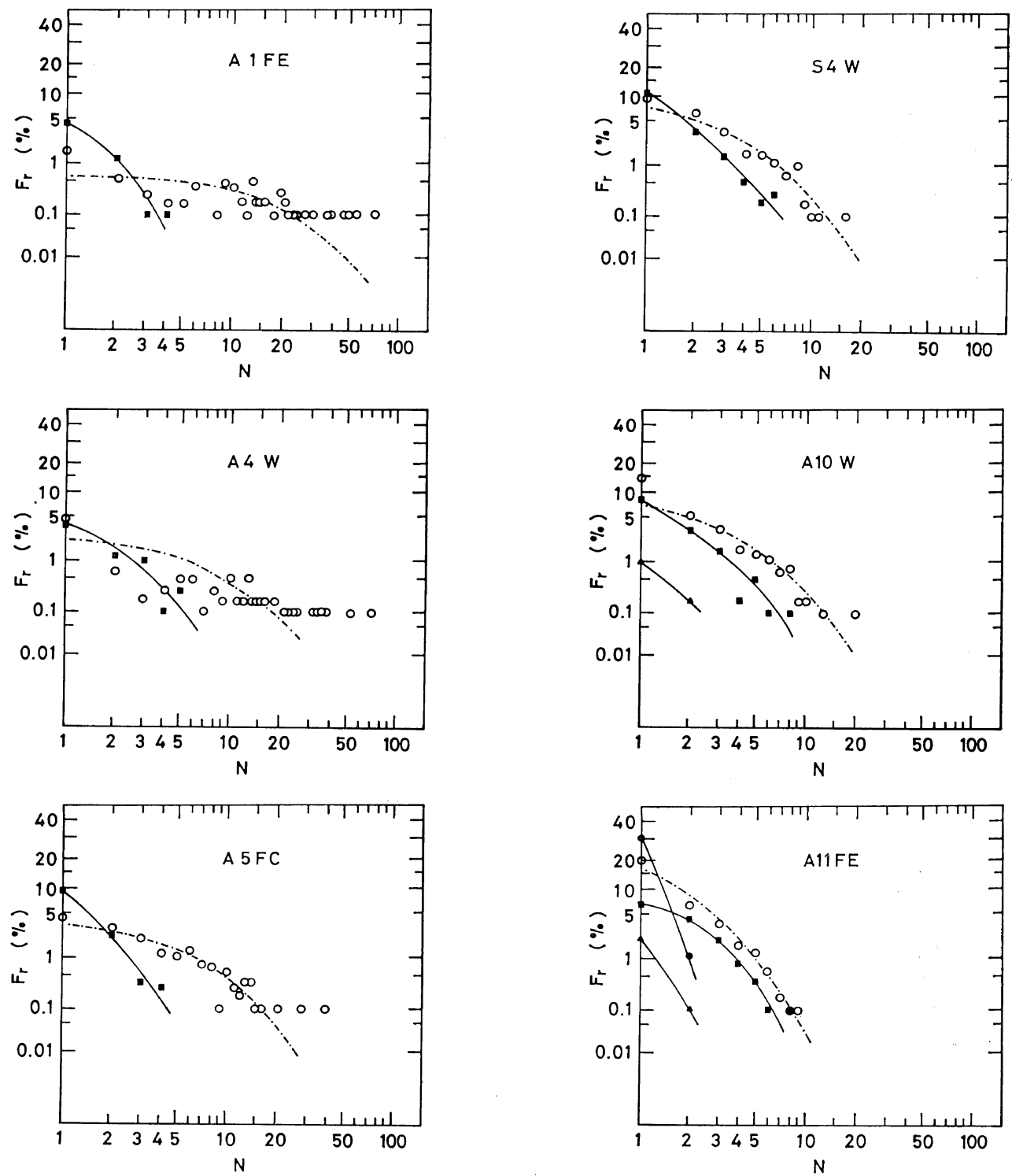

Figure 4. Sequence distribution of various units in the molecular chain of CPE's, HPVC, and VC-Et. $\mathrm{O}, \mathbf{\mathrm { D }}, \mathbf{\Delta}$, and - indicate the frequency to find a unit such as $-\left(\mathrm{CH}_{2}\right)_{N}-,-\left(\mathrm{CHCl}-\mathrm{CH}_{2}\right)_{N}-$, $-\left(\mathrm{CHCl}-\mathrm{CH}_{2}-\mathrm{CCl}_{2}-\mathrm{CH}_{2}\right)_{N}-\mathrm{CHCl}-$ and $-(\mathrm{CHCl})_{N}-$, respectively. The dot-dash-line is that of $-\left(\mathrm{CH}_{2}\right)_{N}-$ by eq 21 . The sample code in the figure is the same code as used in Table VI and Figure 2.

chain. The $\operatorname{Fr}(N)$ 's are summarized in Tables VIII-X, and depicted in Figure 4 as well as that of $-\left(\mathrm{CH}_{2}\right)_{N}$ - Discussions on sequence distribution of various units are as follows.

Low Chlorine-Content Region $\left(X_{\mathrm{s}} \leqq 0.25\right)$. As shown in Figure 4 (A1FE, A4W), the frequency of $-\mathrm{CHCl}-\left(\mathrm{CH}_{2}\right)_{N}-\mathrm{CHCl}-$ is almost equal to $0.1-0.2$ in the region of sequence number, $10 \leqq$ $N \leqq 100$, and these results deviate remarkably from an estimation by eq 21 .

Also it is notable that the unit of $-(\mathrm{CHCl}-$ $\mathrm{CH}_{2}-\mathrm{CHCl}$ ) - is present more than is estimated, 

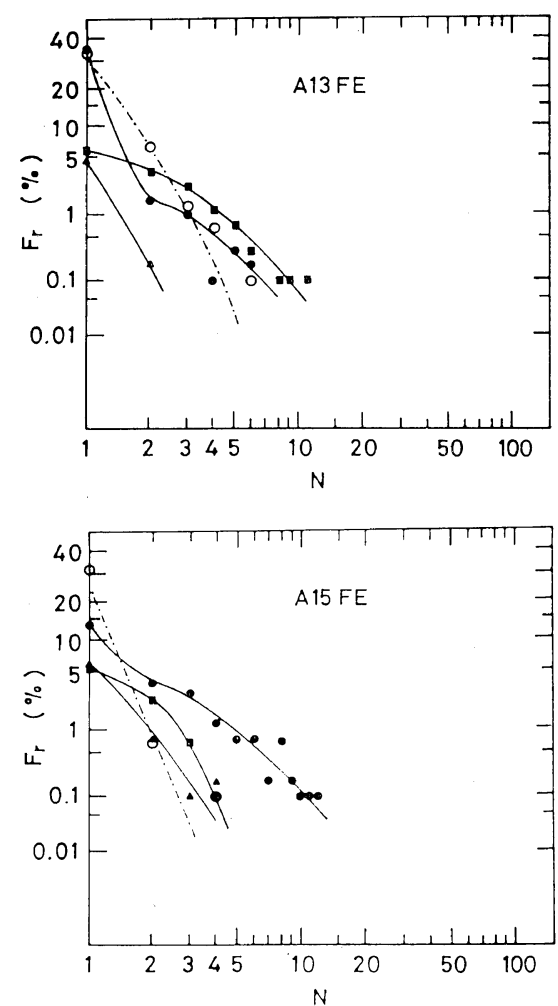

Figure 4. (Continued)
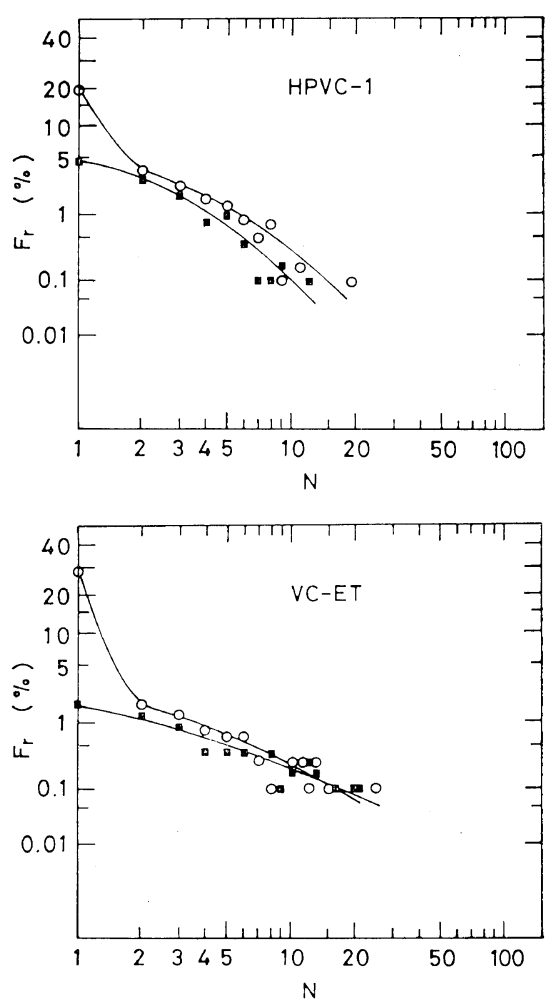

studied by Colebourne, et al. ${ }^{11}$ as shown in Table XI. Therefore, it seems to be a characteristic that 1,3-dichloride units are selectively formed in the CPE molecules even at low chlorine-content.

Middle Chlorine-Content Region $\left(0.25<X_{\mathrm{s}} \leqq\right.$ $0.50)$. Though the frequencies of methylene sequence become considerably close in agreement with those estimated by eq $21, \operatorname{Fr}(1)$ and $\operatorname{Fr}(N \geqq 20)$ of methylene sequences are higher than those estimated as shown in Figure 4 (A5FC, S4W, A10W).

The sequence length of vinyl chloride is still short, viz., $\operatorname{Fr}(N>5)$ of $-\left(\mathrm{CHCl}-\mathrm{CH}_{2}\right)_{N}-$ are less than $0.3 \%$ as listed in Table VIII, then the unit $-\left(\mathrm{CHCl}-\mathrm{CH}_{2}\right)_{N}-(N>5)$ can hardly exist in this region of mean chlorine-content. After the mean chlorine-content approaches $40 \mathrm{wt} \%$, the $\mathrm{CCl}_{2}$ units become observable in a sequence such as

$$
-\left(\mathrm{CHCl}-\mathrm{CH}_{2}-\mathrm{CCl}_{2}-\mathrm{CH}_{2}\right)_{N}-\mathrm{CHCl}-
$$

as listed in Table IX.

High Chlorine-Content Region $\left(X_{s}>0.50\right)$. In this region, long methylen sequence decreases 
rapidly, and the sequence lengths such as $-\left(\mathrm{CHCl}-\mathrm{CH}_{2}\right)_{N}-,-(\mathrm{CHCl})_{N}-$, and $-(\mathrm{CHCl}$ $\left.-\mathrm{CH}_{2}-\mathrm{CCl}_{2}-\mathrm{CH}_{2}\right)_{N}-\mathrm{CHCl}-$ increase more and more with the increasing mean chlorine content as shown in Figure 4 (A11FE, A13FE, A15FE).

At the mean chlorination degree above $60 \mathrm{wt} \%$, the sequence of $-(\mathrm{CHCl})_{N}-$ as listed in Table $\mathrm{X}$ are dominantly formed as compared with other sequences, whereas long sequences of $-(\mathrm{CHCl}-$ $\left.\mathrm{CH}_{2}\right)_{N}-(\mathrm{N} \geqq 10)$ and $-\left(\mathrm{CHCl}-\mathrm{CH}_{2}-\mathrm{CCl}_{2}-\right.$ $\left.\mathrm{CH}_{2}\right)_{N}-\mathrm{CHCl}-(N \geqq 6)$ have only a low frequency even above $60 \mathrm{wt} \%$ of chlorine as listed in Tables VIII and IX, respectively. This is also a characteristic of the CPE sequence.

Comparison of Sequence Distribution of CPE with Those of HPVC, VC-Et Copolymer and $P V C$. The most remarkable difference among the sequences of HPVC, VC-Et, PVC, and CPE is in the sequence length distribution of vinyl chloride unit at nearly equal chlorine content. In the sequence of HPVC and VC-Et, there is pretty long sequence of vinyl chloride unit like that of block copolymers as shown in Figure 4 (HPVC, VC-Et). On the other hand, there is few longer vinyl chloride sequences than five in the CPE molecules as shown in Figure 4 (S4W, A10W). This trend is typically observed in the sequence of CPE of which mean chlorine content is almost equal to that of PVC as shown in Figure 4 (A13FE).

These facts suggest that the hydrogenation of PVC with a cocatalyzer of lithium aluminum hydride $^{12}$ heterogeneously occurs on the surface of the catalyzer and the copolymerization of VC-Et with a catalyzer of trialkyl boron ${ }^{13}$ is rather similar to block copolymerization. On the other hand, the chlorination of PE is seemed to be substantially random substitution reaction. Therefore, the dehydrochlorination-behavior of these polymers will reflect their characteristic distribution of chlorines along the molecular chain.

Mean Sequence-Length of Methylenes and Methynes

The mean sequence length in sequence number of chemical units $(\bar{l})$ is readily calculated by the following equation,

$$
\bar{l}=\sum_{N=0}^{\infty} \operatorname{Pr}(N) / \sum_{N=0}^{\infty} \operatorname{Fr}(N)
$$

where $\operatorname{Pr}(N)$ and $\operatorname{Fr}(N)$ are the existence prob-
Table XII. Mean sequence length of methylenes $\left(\bar{l}_{\mathrm{CH}_{2}}\right)$ and methynes $\left(\bar{l}_{\mathrm{CHC} 1}\right)$

\begin{tabular}{lcrc}
\hline Sample & $\begin{array}{c}\text { Chlorine content } \\
\text { (wt fraction), } \\
X_{\mathrm{s}}\end{array}$ & \multicolumn{2}{c}{ Mean sequence number } \\
\cline { 3 - 4 } & & $\bar{l}_{\mathrm{CH}_{2}}$ & $\bar{l}_{\mathrm{CHC} 1}$ \\
\hline A1FE & 0.163 & 12.03 & 1.00 \\
A4W & 0.219 & 8.09 & 1.00 \\
A5FC & 0.310 & 4.72 & 1.00 \\
S4W & 0.406 & 2.78 & 1.00 \\
A10W & 0.432 & 2.58 & 1.00 \\
A11FE & 0.495 & 1.90 & 1.04 \\
A13FE & 0.578 & 1.28 & 1.17 \\
A15FE & 0.666 & 1.03 & 2.28 \\
HPVC-1 & 0.449 & 2.18 & 1.00 \\
VC-Et & 0.478 & 1.84 & 1.00 \\
\hline
\end{tabular}

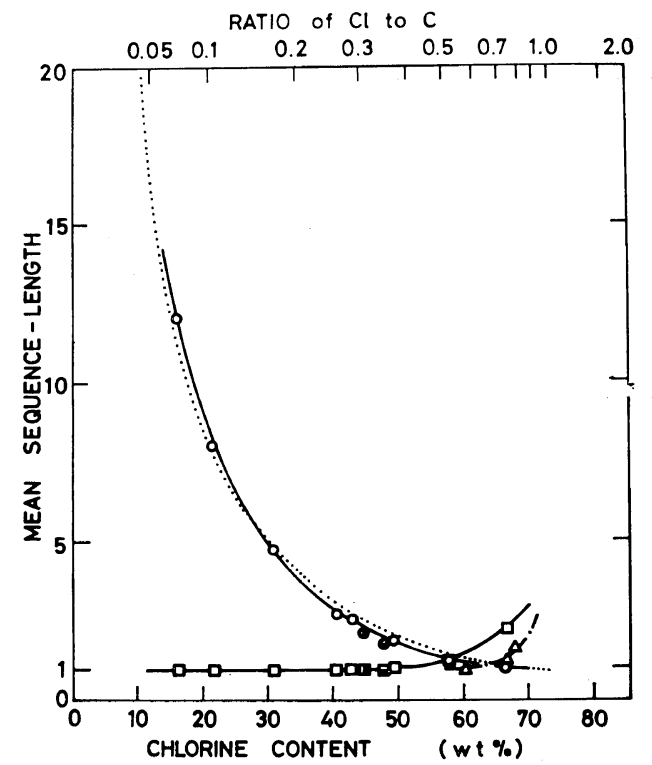

Figure 5. Mean sequence length of methylene and methyne units as a function of mean chlorine content $\left(X_{s}\right) . \bigcirc, \Theta$, and $\Theta$ indicate mean length of methylene sequence of CPE's, HPVC and VCEt, respectively, by the simulation, and the dotted line is a theoretical curve of that by eq 44 in our previous paper. ${ }^{5} \square, \square$, and $\square$ indicate mean length of methyne sequence of CPE's, HPVC, and VC-Et, respectively, by the simulation, and $\triangle$ indicates that of CIPVC provided by Svegliado, et al. ${ }^{14}$

ability and the frequency to locate methylene or methyne sequences in the most probable model sequences, respectively. The results are listed in Table XII and depicted in Figure 5. The 
mean sequence lengths obtained by the computer simulation are in close agreement with those of the statistical calculation by means of Frensdorff, et al.,'s work. ${ }^{7}$

It is also revealed by the simulation thet the mean sequence length of methyne unit are unity below 50wt $\%$ of chlorine, however those increase rapidly above $60 \mathrm{wt} \%$ and that those of CPE are longer than those of chlorinated PVC(CIPVC) deduced from Figure 4 of the paper provided by Svegliado, et al. ${ }^{14}$ Therefore, it can be said that the vicinal dichloride sequence is apt to form in a CPE chain at high chlorination-degree more than in a chain of C1PVC.

\section{CONCLUDING REMARKS}

The most probable model sequence of CPE chain could be determined self-consistently with the aid of a computer simulation on the basis of the triad informations obtained by the NMR spectroscopy. The sequence distribution of various units was also determined by the simulation.

The self-consistency of the simulation leads to extensive remarks that the present method for obtaining the polyad information effects an inspection of evidence of the triad assignments, and it can be generally applied for determining a sequence distribution of other copolymers or substituted polymers on the basis of suitable spectroscopic knowledge when polyad informations are required.

It will be expected that the structure-sensitive properties of CPE such as glass transition temperature, cohesive energy density, refractive index and dehydrochlorination behavior can be discussed in the light of the sequence distribution of chlorines in the CPE chain.

Acknowledgements. The authors would like to thank Messers. Y. Koike and Y. Nishikata for their contribution to the computer simulation.

\section{APPENDIX}

Testing and Application of Pseudorandom Numbers

Pseudorandom numbers, $R D N(I)$ used in the present article are generated by a computer with the multiplicative congruential method as following subroutine; ${ }^{8}$

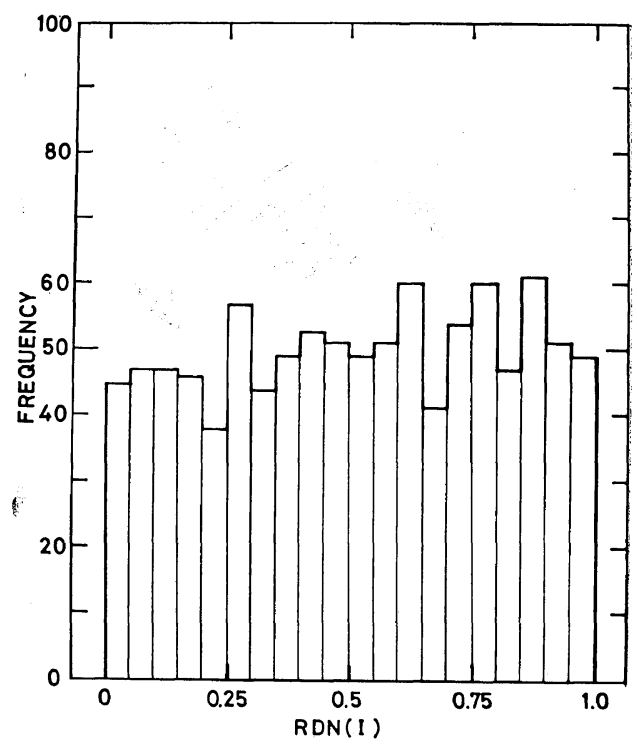

Figure 6. Histogram of one thousand pseudo random numbers, $R D N(I)$, in the range of $[0,1]$; here $X_{0}$ in eq 23 is equal to 63751093 .

$$
\begin{aligned}
& X_{0}=\text { an arbitrary positive odd integer } \\
& \quad \text { less than } 10^{9} \\
& X_{i}=65539 X_{i-1} \quad(i, \text { natural number }) \\
& R D N(I)=0.4656613 X_{i} \times 10^{-9}
\end{aligned}
$$

in this faper, the value of $X_{0}$ is defined to be an integer 63751093.

A histogram of one thousand $R D N(I)$ 's thus generated is shown in Figure 6, from which the distribution of $R D N(I)$ appears to be pretty uniform. However, an independency of $R D N(I+1)$ on $R D N(I)^{15}$ is unsatisfactory except some partial ranges of $[0,1]$ as shown in Figure 7 . Therefore, it is not fully available to apply $R D N(I)$ as generated to the Markovian process. Then, the following operations were used in the present paper:

(i) to divide the range $[0,1]$ into $k$ subranges, i.e., $[(n-1) / k, n / k]$, where $n$ and $k$ are integers $(1 \leqq n \leqq k)$

(ii) to classify $R D N(I)$ into the $n$-th subrange and to rewrite $R D N(I)$ as $R D N(I)_{n}$

(iii) to reduce the conditional probability $P\{\boldsymbol{K} \mid I J\}$ to $\boldsymbol{P}\{\boldsymbol{K} \mid I J\} / k$

(iv) to compare $R D N(I)_{n}$ with reduced conditional probability as shown in eq 15-19 

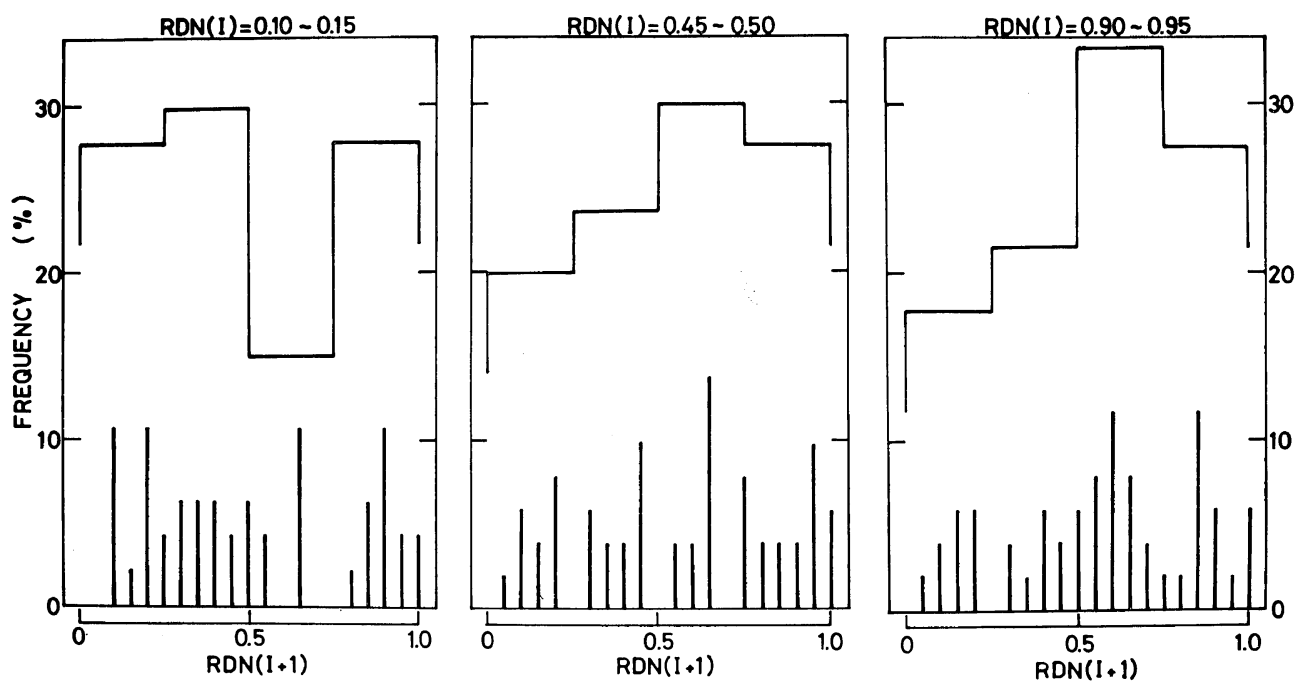

Figure 7. Histogram of $R D N(I+1)$ in the range of $[0,1]$ when the range of $R D N(I)$ is defined. $X_{0}$ is the same as that in Figure 6.

where $k$ is tentatively defined, in this paper, to be five. The convergency of the present calculation was improved by the above operations.

\section{REFERENCES}

1. R. B. Beevers and E. F. T. White, Trans. Faraday Soc., 56, 1529 (1960).

2. N. W. Johnston, ACS Polym. Preprint, 10, 608 (1969).

3. J. Furukawa, et al., J. Polym. Sci., Part B, 7, 561 (1969).

4. T. Horino, et al., Kogyo Kagaku Zasshi (J. Chem. Soc. Japan, Industrial Chem. Section), 73, 1615 (1970).

5. T. Saito, Y. Matsumura, and S. Hayashi, Polymer J., 1, 639 (1970).

6. G. E. Ham, Ed., "Copolymerization" Interscience Publishers, New York, N. Y., 1964, p 5.

7. H. K. Frensdorff and O. Ekiner, J. Polym. Sci.
Part A-2, 5, 1157 (1967).

8. E. G. Brame, Jr., ibid., Part A-1, 9, 2051 (1971).

9. IBM Subroutine, "RANDU" (SSP/360, version 2).

10. T. Saito, Preprint, SPSJ 19th Symposium on Macromolecules, Kyoto, 1970, p 831, $21 \mathrm{D} 06$.

11. N. Colebourne and E. S. Stern, J. Chem. Soc., June, 3599 (1965).

12. J. D. Cotman, Jr., J. Amer. Chem. Soc., 77, 2790 (1955).

13. A. Misono, Y. Uchida, and K. Yamada, Bull. Chem. Soc. Japan, 39, 2458 (1966).

14. G. Svegliado and F. Z. Grandi, J. Appl. Polym, Sci., 13, 1113 (1969).

15. More on the criteria for pseudorandom numbers is discussed in the literature: J. Reitman, "Computer Simulation Applications", WileyInterscience, a Division of John Wiley and Sons, Inc., New York, N. Y., 1971, Chapter 4, P 98. 